\title{
Changing Demographics and Human Capital Development: Implications for Economic Growth in Nigeria
}

\author{
Campbell, Omolara A (Ph.D) \\ Department of Economics, \\ Lead City University, \\ Ibadan. Oyo State. Nigeria. \\ Oluwakemi B. Okuwa, (Ph.D) \\ NISER. Ibadan. Oyo State.
}

\begin{abstract}
The three major drivers of demographic trends are fertility, mortality and immigration. The demographic position in Nigeria has changed in recent years with crude birth and death rates as well as fertility rates falling. As countries move through demographic trends, the size of the working age population increases. Such outcomes have economic consequences, which lead to increase in aggregate income level through expected increase in productivity level. This paper investigates the channels through which human capital development could stimulate economic growth during changing demographics. In our model, the growth of the economy is a function of productivity and productivity itself is a function of demographic trends. Thus, a Two-Stage Least Squares (2SLS) econometric technique was adopted. Our result shows that productivity and investment in education has an elastic impact on the growth of the economy. JEL Classification: I115, I 125, J11, 015
\end{abstract}

Key Words: demographic trends, crude death rates, birth rates, fertility and human capital development

\section{INTRODUCTION}

Demographics are the quantifiable statistics of a given population which characterize that population at a specific point in time. They are referred to as the statistical data of a population especially those showing average age, income, education and vital social statistics of a human population such as the number of births or deaths. Demographic trends on the other hand describe the historical changes in demographics in population overtime. The three major drivers of demographic trends often identified in literature are: fertility, mortality and immigration. Demographic trends lead to demographic transition from high to low rates of mortality and fertility. They are expected to be accompanied by interactions between longevity and education. According to the UN projection, the population of the developed countries will fall by $3 \%$ by 2050 while that of the developing countries will rise by almost $60 \%$. Population densities are rising from 59 to 94 per sq/ $\mathrm{km}$ in the less developed countries. As regards global aging, Cohen (2011) points out that the median age of the world's population rose from 3 years to 26.6 between 1990 and 2000. This rapid aging reflects reduced fertility and longer life expectancy at birth which has increased from about 30 years in 1900 to more than 66years in 2000. Thus the ratio of old (65+) to young (0-4) will likely rise from 1:1 now to 3.3: 1 in 2050. The world dependency ratio (the ratio of the number of people aged 14 years and younger plus those ages 65 and over to the number of ages 15 to 64) peaked 1965 and 1970 and has been falling ever since. The dependency ratio is a measure of a country's age structure. According to 
Cohen's compilation, individual's ages 15 to 64 are workers while others are dependants. However in the developing countries, youths often work while in the industrial countries, they are often in school. At the other end of the age spectrum, the economic burden imposed by aging population will largely depend on the health of the elderly. National longitudinal surveys indicate that chronic disability among the elderly could be declining as fast as $1.5 \%$ a year. Such a rate of decline would likely keep the ratio of the economically active aged 20 to 64 to the chronically disabled 65 high.

High rates of population growth are temporary consequences of the decline in mortality preceding the decline in fertility. The initial mortality decline is concentrated among infants and young children, thus concentrating its effect at the lower end of the age distribution. Also, the subsequent fertility decline has an effect on the age distribution that is, naturally, entirely concentrated at age zero. The combination of these two forces introduces a bulge into the population pyramid. Its leading edge is created by the decline in infant and child mortality and its trailing edge by the decline in fertility. Overtime, the bulge ages and moves from being concentrated among young people to being concentrated at the prime ages for working, saving, reproduction and eventually, to being concentrated at the years of old age. The youths and the old consume more output than they generate, unlike the working age individuals, whose contribution to output and savings tends to be more than commensurate with their consumption. The value of output per capita which is most widely used indicator of economic performance tends to be boosted when the population of working age individuals is relatively large. This tends to be depressed when a relatively large part of the population consists of young and elderly dependents (Higgins, 1998). Also, a fall in the youth dependency ratio permits schooling per child to rise, adding further to future economic growth. As the population age distribution changes over the course of demographic transition and beyond, levels of per capita income will change. This reveals the patterns of economic growth that have proven to be evident in cross- national data. It is noteworthy however, that demographic change which led to high rates of income growth was what became known as the East Asian Miracle. From 1965 - 1990, the working age population of East Asia grew nearly ten times faster than the dependent population. Changes in age distribution of the population can have important economic effects which reflect the influence of changes in the number of working age individuals per capita and shifts in behaviour such as increased savings and greater investment in schooling per child as both desired and completed fertility fall. These effects are determined by government policies, institutions and conditions that determine an economy's capacity to equip its people with human and physical capital and to absorb them into productive employment (Kelly and Schmidt, 1995). These findings confirm that there is strong relationship between economic growth, development and population matters.

Recent literature on the effects of population change and economic growth have two key features in common which conclude that reducing the current rate of population growth does not lead to a corresponding reduction in the current rate of the labour force growth. Also, there is the assumption that links between population and income proceed in one direction, that is, from the former to the latter. The work of Bloom and Fink (2009), confirms clearly that population change affects income growth and changes in income affect population growth mainly through their effect on fertility. These results however confirm the importance of rapid and pronounced demographic change in East Asia on the region's economic success. The population structure in Nigeria for over 40 years after independence has experienced slow demographic transition accompanied with high fertility and mortality rates which resulted in high ratio of children in the population. The demographic position is however changing in recent years with crude birth and death rates as well as fertility rates falling. This trend is 
however expected to continue for the next few decades, which is an indication that the nation is going through a demographic transition (United Nations, 2007). As countries move through demographic trends, the size of the working age population increases. Such outcomes have economic consequences which lead to increase in aggregate income level through expected increase in productivity level. This is possible through investment in human capital which enhances accumulation of inputs in the form of knowledge and skill acquisition. Changes in education acquisition have a substantial impact on fertility patterns and demographic composition. Fertility differentials exist among skilled and unskilled individuals. This has to do with education acquisition. Accumulated education acquisition affects fertility decisions of individuals and the quantity-quality trade-off. Increased technological acquisition, improved wages brings about improvements in life expectancy. These induce incentive to acquire human capital. The Human Development Index (HDI) measures a country's overall achievement in its social and economic dimensions- based on health of people, their level of education attainment and standard of living. Available data indicate that Nigeria with HDI of 0.0448 in 2004 was ranked 159 on the global ranking of 177 countries, which places Nigeria as one of the low human development countries. However between 2005 -2012, the HDI figures for Nigeria rose from 0.434 to 0.471 , but fell below sub-Saharan African countries in most of the years and very much below the world average. The basic indicators of human development: HDI - Health, HDI- Education and HDI - Income, ranged between 0.404 and 0.510 . The latest HDI for Nigeria in 2013 is 0.482 , placing the country in 153rd position out of 187 (UNDP, Human Development Reports, Various Years). From the forgoing statistics, it is clear that human development condition in Nigeria is far from the expected.

With this background, this paper investigates the effect of human capital development on economic growth during changing demographics. The study employs time series data for Nigeria for the period of 1990-2010. It is applied to a Two-stage least square (2SLS) which is a special case of instrumental variable regression (Oyinlola, 2012). The paper is structured in seven sections as follows respectively: Introduction, Nigeria's Demographic and Economic Profile, Demographic trend/ Dividend, Brief Theoretical and Empirical Review, Human Capital, Demographics and Economic Growth - The Nexus, The Model, Results, Conclusion and Recommendations.

\section{Nigeria's Demographic and Economic Profile}

Nigeria is the most populous country in Africa with a current estimated population of about 175 million (CIA World Fact book). It is characterized by a high growth rate of about 3 percent per annum. As a result, the population has increased from about 57 million people in 1963 to 140 million (more than double) at the time of the 1991 census. By 2012, the data collected by the National Bureau of Statistics indicate that the total population of citizens in Nigeria was around 166.2 million which increased to an estimated 175 million in 2013(Makinwa Adebusoye, 2014). By 2014, however, the population is estimated to have increased to 178.5 million people. The United Nations project that the overall population in Nigeria will reach 210 million by 2025 and about 390 million by the end of the year 2050 despite the declining fertility rates. Meanwhile, the Census Bureau of the United States predicts 402 million people for Nigeria by the end of 2050 and that this will reach 730 million by 2100 . The entire population of Nigeria accounts for about $2.5 \%$ of the entire World population. Nigeria is the 7 th most populous in the world, with about $33.3 \%$ of this constituted by young people. Nigeria has the largest labour force (11th in the world). Further UN projections indicate that most of Nigeria's demographic growth will be in people of working age (15-64). Dependency ratio (the number of children and elderly divided by the number of working age adults) declined from 83 dependents per 100 workers in 2010 which is estimated to decrease to only 50 dependents per 100 workers by 2050. Nigeria has over the years experienced high mortality rate due to 
rampant HIV/AIDS epidemic in the country. This has improved significantly over the last 15-20 years. However, compiled/ estimated data from UNDP (2011) indicate that crude death rate is falling in recent years and has the tendency to continue to fall ranging from 21.1, 13.7 and 7.7 deaths per thousand population between 1970 -2015 and estimation covering 2015-2050 respectively (World Population Review, 2014).

Life expectancy in Nigeria is unfortunately the lowest in West Africa. For both men and women, life expectancy at birth ranged between 46years and 52 years from 1980 to 2013 (UNDP, 2013). This low age can be attributed to the fact that Nigeria has a lot of health issues to contend with. Such include: HIV/AIDS epidemic, child and maternal mortality rate coupled with the widespread growth of the polio virus. As regards infant mortality rate, over several decades, the under-five mortality rate like the Total Fertility Rate has remained high though slowly decreasing. It decreased from 201 child deaths per 1,000 live births around 2003 to 128 child deaths per 1,000 live births around 2013. This is an indication that Nigeria is far behind the target set by the Millennium Development Goals (MDG) and farther behind the Policy on Population for Sustainable Development (2004) of reducing, by 2015, the under-five mortality to 45 deaths per 1,000 live births. Maternal mortality is also a great issue in Nigeria. Nigeria's current fertility rate of 5.5 births per woman is much higher when compared with that of other African and developed countries (Makinwa- Adebusoye, 2014). Nigeria's demographic trends are of particular importance because Nigeria is expected to make up 3\% of the total world population and $14 \%$ of Africa's population by 2050. According to the Census Bureau of Population, this technically means that 1 out of every 43 people in the world is from Nigeria. Nigeria has the capability of being a major player in the global system and a particularly important actor on the African continent if it develops its human capital. The re benchmarking/rebasing of Nigeria's GDP has placed the country as Africa's largest economy and has exposed its investment potentials to the world. The exercise reveals that the nominal GDP in 2010 was reversed from 33.9 trillion naira to 54.2 trillion recording an increase of 59.5\%. In 2011, GDP was recorded as 34.4 trillion and this was reversed to 63.3 trillion naira, an increase of $69.1 \%$. For 2012, the GDP was reversed from 40.5 trillion to 71.1 trillion, recording an increase of $75.58 \%$. Estimates show that for 2013, the GDP was reversed from 42.3 trillion naira to 80.3 trillion, recording an increase of $89.22 \%$. Industry on the other hand when rebased dropped from $46.08 \%$ to $25.81 \%$, while service has more than doubled to over $50 \%$ from 23\% (World Bank, 2014). It is however clear from this statistics that the structure of the Nigerian economy has changed significantly. The unanticipated rise in the Nigerian population over the last five years has been described as a potent threat to the future of the nation's economy unless properly managed by the federal government. A large uneducated working age population will increasingly put a country at risk of political and economic instability.

\section{Demographic Trend and "Demographic Dividend"}

The demographic dividend is the accelerated economic growth that may result from changes in a country's population age structure. This has to be accompanied with strategic investments in public health, education, family planning, labour market flexibility /expansion, openness to trade and savings, appropriate economic policies and governance. Shifts in age structure are driven by a transition from people living short lives and having large families to live long lives and have small families. These changes usher in better living standards for families and higher incomes per person, based on the assumption that the right policies are in place. This gives rise to a growing working age population which increases incomes per person and spurs a country's total economic growth. Evidence from literature indicates that East Asia and Latin America are at the forefront of demographic transition. This trend has however continued even 
in subsequent years. Demographic dividend is derivable from demographic transition via favourable age composition of population, that is, larger percentage of the population falling within the working age (15-64). Demographic transition offers policy makers a window of opportunity which enhances economic and social development. Demographic transition via population growth has a large statistically significant negative effect on per capita income (Bongaarts and Casterline, 2012).

The increase in the working age share results from a lag between declines in mortality and fertility, creating a "baby boom" generation, which tends to be larger than others in the population. It should however be noted here that the baby boom generation must be fed, clothed, housed and educated when it is young and even as it grows. This places substantial burden on families and the wider society. However the good news here is that, as this generation enters its working years, and number of dependents decline, due to falling fertility, there is potential for a sizeable boost to economic growth. The dividend from a favourable demographic transition requires good governance, effective public policies accompanied by an enabling environment.

Nations undergoing demographic transition have the added advantage of "demographic dividend" derived from favourable age composition of population. Such window of opportunity is vital to the economic and social development of their countries. Labour market rigidities common in many developing countries, such as rules governing the hiring and firing of workers, fixing of minimum wage rates that discourage hiring new hands in production and training the existing workers, can impede on the potential demographic dividend. Another important component of demographic dividend is long-term fertility rate decline which opens the window of opportunity for the dividend. Access to voluntary, right -based family planning coupled with improved health and decreased desire for family size, leads to fewer children and a growing share of working - age adults. The shift in the age structure that comes with investments in family planning ushers in the window of opportunity of a demographic dividend (Goujon, 2006).

Demographic dividend is delivered through a number of mechanisms: (i) Labour Supply: (a) when the generation is between 15 and 64, it is more likely to be working thus lowering the ratio of dependants to non- dependants. During the peak working years of 25 to 29, this effect is especially strong since the labour supply is substantial and provided the labour market absorption capacity is high, per capita production of worker increases. (b) As family size declines, women are more likely to enter the labour force. Such adult women are however assumed to be educated and brought up in small families. The assumption here however is that their education increases their productivity in the labour market. (c) Demographic transition also encourages the growth of savings thus increasing the country's capability for investment and growth. The working population tends to contribute to a high level of economic output and also higher level of savings. People tend to save between the ages of 40-65 when they are less likely to be investing in their children but rather prepare for retirement. (ii)Human Capital: Demographic transition has significant effects on investments in human capital. Demographic transition along with educational investment that creates jobs for the growing working-age population can also encourage a demographic dividend. The size of the dividend depends on how fast the support -ratio, that is the proportion of working people to non-workers increases. Related to this is the investment in education of youth which contribute immensely to demographic dividend. This implies that, countries all over the world are expected to have large numbers of people entering the workforce each year. Thus, investing in the education of youths through education is critical to seizing the demographic dividend. 
Demographic transition begins with changes in mortality that results in a population that lives longer and stays healthier. A longer life expectancy causes fundamental changes in the way that people live. Other factors such as attitude to education, family retirement, the role of women at work are all relevant to longer life expectancy. The positive correlation between education and earnings cannot be overemphasized here. As life expectancy increases, parents are likely to choose to educate their children to more advanced levels. On the other hand, healthier children have greater potential to experience cognitive development per year than their less healthy counterparts. (UNDP, 2013).

It is important to note that, since women and girls are $50 \%$ of the world's population empowering them is essential for achieving the demographic dividend. With women and girls having access to education, economic opportunities and rights, countries benefit from increased economic growth and development. Growth in income per capita, with decline in fertility rate as predicted by the UN medium fertility variant, per capita income could be boosted by $6.5 \%$ in Nigeria and almost $27 \%$ in Ethiopia (UNDP, 2013).

The standard UN definition which is also used by the International Labour Office, classifies "youth" as those between 15-19 years (teenagers) plus those 20-24 years, that is, the youths are those between 15-24 years old (ILO, 2012). The definition however often varies from country to country. Recent data from the ILO (2012) showed that globally, one person out of every five is between the ages of 15 - 24 years. Altogether, there are over 1.2 billion youths in the world, majority of them (about 90\%) live in developing countries, with $60 \%$ in Asia, and $17 \%$ in Africa (14\% from sub-Saharan Africa- SSA and 3\% from North Africa). While a youthful population is an important asset for innovation and creativity in economies and society, to realize this 'youth dividend', young people have to be productively employed and integrated into society (ILO, 2012).Low employment rates and earnings in SSA is another barrier to exposure to a demographic window. Countries such as Nigeria, Kenya and South Africa have very low economic contributions to youths. This has been identified in low support ratios, poor employment opportunities for youths, low female labour participation accompanied with low levels of labour income among African Youths.

\section{Brief Theoretical, Empirical and Methodological Review}

Appleton and Teal (1998) examined Africa's achievements in the formation of human capital, and its impact on economic growth and welfare in a cross sectional analysis. The authors noted that even though Africa has made commendable efforts in raising the literacy rate and school enrolments and improving health, the human capital formation in the case of both education and health in Africa are still low comparable to those in other developing nations. Mankiw, Romer and Weil (1992) re-examined the implications of the Solow growth model for convergence in the standard of living of nations. Using a natural regression model fitted into data for the period 1960-1985 comprising of 98, 75 and 22 countries for 3-samples respectively, the evidence shows that international differences in income per capita is best understood using the augmented Solow growth model. In this model, the authors suggest that differences in savings, education and population growth explain most of the variations in cross-country per capita income. This model has several implications for the entire economy. Contrary to Romer's suggestion, there are no substantial externalities to the accumulation of physical capital; it receives its share of social returns. Despite the presence of no externalities, the accumulation of human capital has a larger impact (the elasticity is one) on income per capita than the textbook Solow model implies (the elasticity in the textbook model is one half). Therefore, a higher savings rate leads to higher income in steady state, which consequently leads to higher level of human capital even if the rate of human capital accumulation is 
unchanged. Also, population growth has a larger impact on per capita income than the textbook model suggests; in both models higher population growth lowers income and total factor productivity, however, the degree is quantitatively different. In the textbook Solow growth model, the elasticity of income per capita with respect to population growth is -0.5 , however, in this augmented model, the impact is -2 . In contrast to the endogenous growth models, the study predicts that countries with similar technologies and rates of accumulation and population growth should converge in income per capita. However, this convergence occurs more slowly than the textbook model implies. The textbook Solow model suggests that the economy reaches half-way to steady state in about 17 years while this model suggests about 35 years. In summary, it is widely acknowledged in theory and empirical analysis that the quality and quantity of education of a country explains the per capita income divergences of a country, leading to the variation across country growth and development experiences. Based on the submission above, the underlying theoretical background for this study is based on the Solow - Swan neoclassical growth model. The model assumes the production function is $\mathrm{Y}=\mathrm{F}(\mathrm{K}, \mathrm{L})$ where $\mathrm{Y}=$ income, $\mathrm{K}=$ capital and $\mathrm{L}=$ labour. With the assumption of constant returns to scale, we have the production function re -written as $Y / L=F(K / L, l)=L . f(K)$, where $\mathrm{Y}=\mathrm{Y} / \mathrm{L}$, which is output or income per worker. $\mathrm{K}=\mathrm{K} / \mathrm{L}$, which is capital/ labour ratio. The production function can thus be expressed as $\mathrm{y}=\mathrm{f}(\mathrm{K})$. In the Solow - Swan neoclassical model, saving is a constant fraction, $\mathrm{s}$, of income. Saving per worker is sy and since income equals output.sy $=$ sf $(\mathrm{k})$. The investment required to maintain capital per worker $\mathrm{K}$, depends on population growth, and the depreciation rate $d$. Since the assumption is that investment required to maintain capital per worker $\mathrm{K}$, depends on population growth, and the depreciation rate, $n$, the capital stock grows at the rate of $n$, the capital stock grows at the rate $\mathrm{n}$, $\mathrm{k}$ to provide capital to the growing population.

Since depreciation is a constant, $\mathrm{d}$, percentage of the capital stock, $\mathrm{d}$. $\mathrm{k}$ is the investment needed to replace worn-out capital. The depreciation investment per worker, d.k is added to $\mathrm{nk}$, the investment per worker to maintain capital - labour ratio for the growing population. Thus: $(\mathrm{nk}+\mathrm{dk})=(\mathrm{n}+\mathrm{d}) \mathrm{k}$, which is the investment required to maintain capital per worker. The net change in capital per worker (capital - labour ratio) over time is the excess of saving per worker over the required investment to maintain capital per worker. Hence, $\mathrm{k}=\mathrm{sf}(\mathrm{k})-$ $(\mathrm{n}+\mathrm{d}) \mathrm{k}$. This is the fundamental equation for the Solow Swan neoclassical model, where the steady state corresponds to $K=0$. The economy reaches a steady state when $\mathrm{sf}(\mathrm{k})=(\mathrm{n}+\mathrm{d}) \mathrm{k}$. The model therefore concludes that the growth rate of output in steady state is exogenous and is independent of the saving ratio and technical progress. Also, if the saving rate increases, output per worker increases through increase in the capital per worker, but the growth rate of output is not affected. Finally, growth in per capita income can either be achieved by increased saving or reduced rate of population growth. This will hold if depreciation is allowed in the model.

Other scholars have identified the fact that changing age structure, health, skill level(represented by formal education), fertility and mortality rate jointly characterize a person's human capital and influence his/her productivity. Bloom and Williamson(1998),Bloom and Canning(2000), emphasized the fact that the realization of the demographic dividend in East Asia was possible since social, economic and political institutions and policies were in place which allowed them to realize the growth potential created by the transition. The authors introduced the neoclassical growth model and applied the conditional convergence model with adequate considerations given to growth of population, growth of workers, growth rate of real gross domestic product, average years of secondary schooling in the initial period, life expectancy, a measure of natural resource abundance, degree of openness, an index of individual quality, average government savings 
and so on. The authors ended up to consider three channels through which population dynamics affect economic growth. These are: labour market effects, effect on savings and capital accumulation and an effect on educational enrolment and human capital

Using micro - data from 48 developing countries, Vogl (2014) found out changes in cross sectional patterns of fertility and child investment over the course of the demographic transition. His result support the model in which rising skill returns lowered the minimum income at which parents invest in education. Bloom, Canning and Fink (2009) in their own study examine the links between demographic change and economic growth in Asia. Results indicate that overall rate of population growth had little effect on economic growth. However, changes in life expectancy, age structure and population density have significant impact on growth rates. In an analysis of micro - demographic data from a rural community in Nepal, Axinn (1993) indicate that children's schooling exerted a strong influence on parents' fertility preference and behavior. Meanwhile, in a different context, Ogawa and Retherford (1993), in a survey conducted among women in Japan cited concerns of women on economic and psychological costs involved in taking fertility decisions and educating children. Bloom and Williamson, 1998, Bloom, Canning and Malaney, (2000), identified the fact that the growth rate of the working population not only determine the accounting effect, which is (the difference between the growth rate of the working age and the total population) but also influences the behavioral component (the productivity term as presented by the growth rate of output per worker). Furthermore, Kelly and Schmidt, Bloom and Williamson (1998) submit that there is a positive effect of the economically active population on growth in output per capita. They found a significant interaction between demographic variables and policies. Good policies lead to higher economic growth and the impact of demographic change is greater when institutions are of higher quality.

A positive relationship has been found between women's education and demographic outcomes in a comprehensive review by Jejeebhoy (1996). In a related research, Oni (1985) conducted a study on urban Nigeria and recorded a higher fertility among more educated women than the less educated women. Subbarao and Raney (1995) utilizing a multi- sectoral approach to the effect of education on changing demographics observed that educational expansion and reproductive health services exert a powerful effect on fertility and infant/child mortality. In addition, simple correlation studies have established that per-capita output growth is influenced by various dimensions of demography (population growth, size and density) Kelly and Schmidt (1995).

Empirical evidence supporting the interaction between fertility, education and economic growth on Tunisia has been investigated by (Frini and Muller, 2012). The study actually attempted to analyse the impact of fertility transition on education and economic growth. The key explanatory variables include: real GDP per capita, infant mortality, contraceptive use ratio and students' enrolment at all levels. With a multivariate cointegration analysis being applied to time series data, a long term triangular relationship was established. This implies that education is found to trigger fertility transition both in the short and long-run. Furthermore, the variance decomposition and impulse response function indicate that the fertility transition has produced a feedback effect on both education and economic growth.

This study however takes a different dimension entirely by investigating the effect of human capital investment on economic growth during changing demographics. This is an entirely new dimension to the discussion on the subject matter. 


\section{Human Capital, Demographics and Economic Growth - The Nexus}

Adam Smith, a foremost classical economist referred to human capital as the talents and skills acquired by the residents of a country. This he sees as part of the country's capital stock since it increases the wealth of the nation and citizenry. Thomas Malthus on the other hand, in his dynamic growth model proceeds to build on the submissions of Adam Smith by emphasizing the fact that, when incomes exceed the equilibrium level, mortality and fertility rate rises and vice-versa. The neoclassical economists, Solow, (1997), Swan (1956), Schultz (1961), Arrow (1962), Becker, (1962 and 1964) came up to introduce other dimensions of human capital and economic growth. They emphasized the fact that the rate of growth of any economy is a function of technological accumulation; ignoring the fact that technology is driven by human capital while it has no capacity to translate to economic growth on its own. From these analogies, human capital remains the bed rock of sustainable growth and development. Schultz (1961) in his own submission argues that there are five ways of developing human capital. Such include: (i) the provision of health facilities, which affect life expectancy, strength, vigour and vitality of the people. (ii) The provision of on - the-job training which enhances the skill of labour force. (iii) Improving education at primary, secondary and tertiary levels. (iv) Enhancing the study and extension programmes for the adults. (v) Provision of adequate migration facilities to individuals adjusting to better job opportunities.

Also, the empirical evidence of Romer (1986), Lucas (1988) corroborates the fact that human capital is a major driver of economic growth and macroeconomic performance of any nation. Overtime, various theorists have proved that humans are the most important and potential source of productivity and growth in a nation. Human capital is a source of both increased productivity and technological advancement. This implies that innovations, equipment and technology are engineered by human beings made realistic by creative thinking, which is a product of the human mind. It is important to note that, each of the components of human capital; education and health has been proven to have a remarkable impact on economic growth. Education has strong impact on labour productivity, the rate of innovation, healthy living and technological improvements. Increased stock of knowledge raises productivity in both firms and households. Increased productivity is transmitted to increased wages, improved access to health products which ultimately leads to higher growth and a general improvement on the aggregate living standard.

As regards the health component of human capital, its availability generates more earnings which accumulate into wealth in the long run. Increase in the aggregate stock of health determines the total amount of time to be spent earning money. The stock of health depreciates with age and therefore has to be increased and improved by continuous investment. This is where government's intervention is required especially in an economy that is not capitalistic in nature. As health improves growth, by making more market time available for the workers to generate income, it also results in a reduction in the mortality rate and reduces fertility rate. This contributes grossly to the voluntary population control. Ranis (2004) indicate a 2 - way relationship between economic growth and human development (which he used interchangeably with human capital. According to him, the levels of economic growth and human development are mutually reinforcing, either leading to an upward spiral of development or a poverty trap. Pritchett (1997) explained this further by identifying the fact that rapid productivity growth was never sustained in the poor regions of the world due to the fact that although countries have equal access to the same stock of knowledge, there are gross differentials in their utilization.

Human capital like physical capital is an important factor input which can be accumulated overtime to increase the economic productive capacity/ potential (Lucas, 1988). Human capital 
accumulation is ultimately linked to other development phenomena such as income distribution and demographic transition. Human capital accumulation reduces young adult mortality, which in turn induces lower fertility. Furthermore, lower fertility reduces the cost of human capital investment, and thus parents increase their human capital investment per child .This leads to a vicious cycle in which human capital growth leads to lower fertility and more rapid human capital growth. Investments in girl's education play important role in promoting demographic changes that enhances slower population growth. Increased education increases the mean length generation which has to do with the amount of time a cohort of women take to reproduce itself. Better utilization of public health and family planning services, higher infant and child survival rates /reduced fertility preferences are important outcomes of increased investment in education. Societies characterized by high mortality and fertility levels for instance typically have social structures and economic incentives that encourage high fertility

Educational expansion/acquisition influences the number of births within a family and also determines the timing and desirability of child bearing. We proceed to introduce the link between maternal education and child survival. This has been well documented in literature. The line of reasoning is that educated mothers compared to their uneducated counterparts attach a higher value to the health and welfare of their children. A strong relationship exists between maternal education and child health after controlling for socioeconomic status. An association between education and knowledge of health interventions has also been identified in literature. Such interventions include immunizations (controlling infant mortality) and contraceptive use (planning fertility). Education is viewed as promoting openness to new ideas not only about mortality and fertility but also about family roles and structures (Caldwell, 1982).

\section{Stylized Facts on Government Expenditure in Education and Health in Nigeria (Budgetary Figures)}

If government investment in education and health is key to sustainable growth as argued in economic literature, then it is worthwhile reviewing the trend over the years. It is clear that the Nigerian government has not met up with the 26 per cent minimum budgetary allocation to the education sector as recommended by UNESCO. The education sector has been grossly underfunded in Nigeria. The 2012 budgetary allocation of N400.15billion representing 8.43 per cent of the total budget contrary to the UNESCO recommendation is abysmal. According to a breakdown of the 2012 budget, 82 per cent and 18 per cent were allotted to both recurrent and capital expenditure respectively. While Nigeria spends less than 9 per cent of her annual budget on education, Abayomi (2012) reveals that Botswana spends 19 per cent, Swaziland 24.6 per cent; Lesotho 17 per cent, South Africa 25.8 per cent, Cote d'Ivoire 30 per cent, Burkina Faso 16.8 per cent, Ghana 31 per cent, Kenya 23 per cent, Uganda 27 per cent, Tunisia 17 per cent, and Morocco 17.7 per cent).

From 1980 till date, empirical data show that government investment in education and health in Nigeria has been on a continuous decrease in real terms. For instance, in 1980, government expenditure in education was N3123.26m. From 1982-1999 (a period of twenty years) real government expenditure in education decreased continually in this manner; $-36.5,-7,-17$, $13.5,-4,25.4,-41.7,38,64.1,8.93,-42.65,-47.04,174.38,12.56,7.08,20.50,-2.44$, and 3.97 (figures are in percentages). From 2000-2012, however, the allocation recorded a gradual percentage increase in the following order; $4.67,10.03,-28.87,88.18,-29.39,18.04,22.85$, $33.73,8.48,1.8,-19.44,4.93,46.11$, and $22.47 \%$ respectively. In 2000, government expenditure in education increased by four percent, it also recorded a continuous increase from 2004-2008, however, it took a down-turn in 2009 and grew again from 2010-2012; 5\%, 
$46 \%$, and 23\% respectively. Given the continuous increase in inflation and sectoral price differences, while the government ensures a continuous increase in the budgetary allocation to both the education and health sectors, in real terms, this allocation have been on a continuous decrease. Empirical evidence in education expenditure shows that the government is far away from complying with the $26 \%$ minimum budgetary allocation to education as advocated by UNESCO.

Heads of State in Africa met from 26-27 April 2001 at a special summit to address the exceptional challenges of HIV/AIDS, tuberculosis and other related infectious diseases. At this meeting, the governments committed to allocating at least $15 \%$ of their total annual government budgets to the health sector. Since 2001, a number of countries have made progress in increasing their domestic funding towards the Abuja 15\% target. The WHO states that only Rwanda and South Africa have reached 15\%, while the African Union Commission reports that six AU member states have met the 15\% benchmark - Rwanda (18.8\%), Botswana (17.8\%), Niger (17.8\%), Malawi (17.1\%), Zambia (16.4\%), and Burkina Faso (15.8\%). The health sector was not spared either, in 1980, the government allocated N609.61m in real terms to the sector. From 1981 to 2012, the sector recorded an initial percentage growth of 595.6\% and gradually decreased in the following manner; $-23.3,-18.47,-15.06,-4.32,26.73,-42.83$, $17.05,44.4,2.14,-39.22,-68.33,95.48,-12.96,15.62,5.74,-7.34,-19.11,35.53,-20.40,97.55$, $45.32,-38.88,50.65,15.06,43.11,-4.21,13.61,-4.06,9.81,30.80$ and 34.27 respectively.

\section{Economic Growth in Nigeria (GDP per worker employed)}

There are various indicators of growth and many authors have chosen them based on various reasons. Generally, the various indicators could be compressed into Gross Domestic Product (GDP) and Gross National Product (GNP). Conventionally, GDP is most popularly used; however, the form of GDP used depends on the objectives set to be achieved by the author and the nature of the work carried out. In various works we see researchers using GDP nominal values, real GDP, GDP per capita and most recently GDP per person employed, which is in line with Durlauf, Johnson and Temple (2004) and Jones (1997) that it is a better measure of productivity and growth. Therefore, in this analysis, the focus is on economic growth measured by GDP per person employed. In the early years of the review period, the economy barely grew. From 1981-1999, the economy recorded almost consistent negative growths for a period of fourteen years. For instance, in 1981, the economy recorded a negative growth of $-11 \%,-3 \%$ in $1982,-9 \%$ in $1983,-6.2 \%$ in $1984,-0.1 \%$ in $1986,-0.2 \%$ in $1987,-3 \%$ in $1991,-2 \%$ in 1992 , $0.7 \%$ in $1993,2 \%$ in $1994,3 \%$ in $1995,0.1 \%$ in $1997,-0.12 \%$ in 1998 , and $2.3 \%$ in 1999 . Not until the early 2000s till date did the economy grow consistently; it recorded scanty growth of 7\% in 1985, 4\% in 1988 and 1989 respectively, and 2\% in 1990 and 1996 respectively.

\section{The Model}

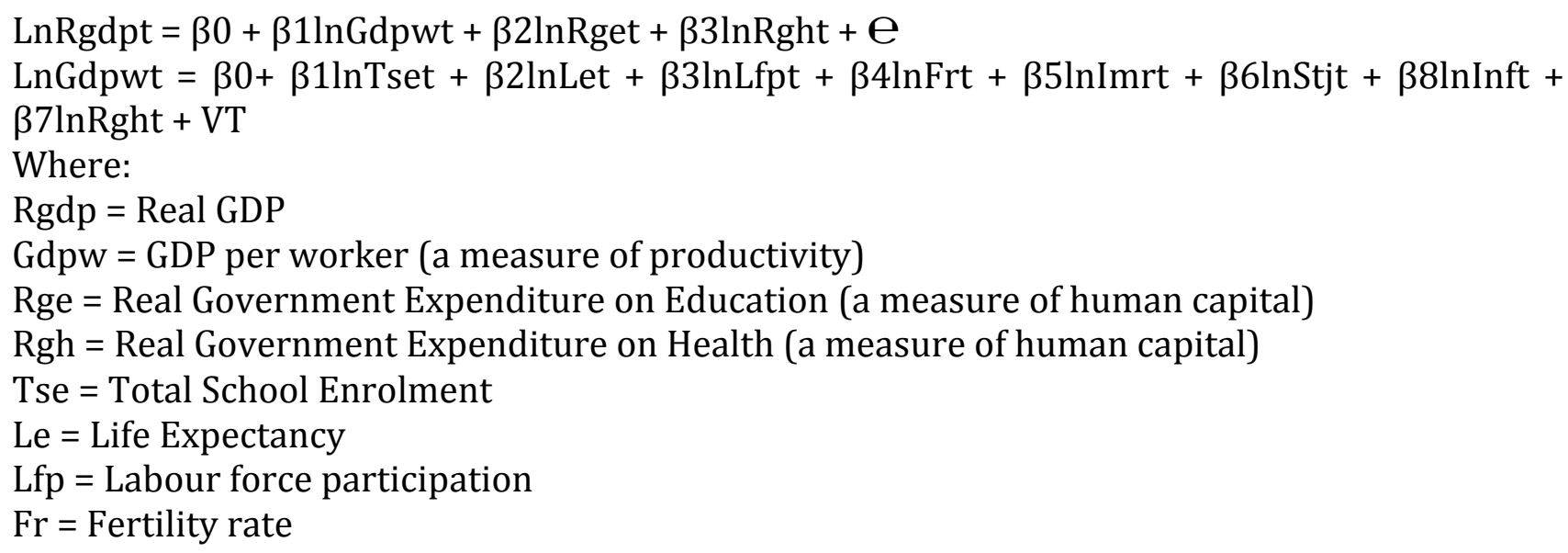


Imr = Infant Mortality Rate

Stj = Expenditure on Science and Technology Journals

$\mathrm{INF}=$ Inflation

In our model; the growth of the economy is a function of productivity (GDPW) and investment in human capital (RGE \& RGH) and productivity itself is a function of demographic trends. All secondary data utilized in this study were basically obtained from National Bureau of Statistics, 1990-2010 and World Bank Publications. A fundamental assumption of OLS is that the regressors are uncorrelated with the disturbance term. Should this assumption be violated, both the OLS and weighted least squares are biased and inconsistent. Where this violation is observed, the standard approach to redeeming the situation is the application of instrumental variables. The basic idea behind instrumental variables is to "find a set of variables, termed instruments, which are both correlated with the explanatory variables in the equation and uncorrelated with the disturbances". The instruments are used to eliminate the correlation. The Two-Stage Least Square (2SLS) is a special case of instrumental variable regression (Oyinlola, 2012). Having observed the endogeneity of productivity in the model, the researcher has chosen to use the 2SLS econometric technique while the following demographics are specified as instruments; LNTSE LNLE LNLFP LNFR LNIMR LNSTJ LNINF LNRGH (see table 1)

\section{SLS DIAGNOSTICS}

a) Instruments Validity Tests - J Statistics

The instrument rank is the number of instruments used and the accompanying test is the J-statistics (along with its p-values).The J-Statistics is used as a test of overidentifying restrictions; the larger it becomes, the more likely it is that the model is incorrectly specified and/ or that the instruments are invalid, however, the smaller it is and if it is insignificant, it suggests that the instruments are valid. A J-statistic of 7.142743 and a Probability of 0.210239 indicate that instruments are valid and well specified.

b) Stability Diagnostics: Model Specification Test; Ramsey RESET Test

Ramsey proposed RESET (Regression Specification Error Test) which is a general test of specification. Specification errors may arise from omitted variables, incorrect functional forms and correlation between the error term and the explanatory variables. The test reports the F-ratio and the log-likelihood ratio for testing the null hypothesis that the coefficients on the powers of the fitted values are all zero, i.e. the equation is wrongly specified. Gujarati and Porter (2009) and Orekoya and Olowookere (2012) have opined that when the test-statistics are significantly different from zero at the chosen level of significance (when it is not significant) we reject the null hypothesis and conclude that the equation is correctly specified. Given that the probability of the F-statistic is not significant, we reject the null hypothesis and conclude that the equation is correctly specified (Table 2)

c) Endogeneity/Instrument Orthogonality C-Tests Test

The OLS assumption that the error term be uncorrelated with the explanatory variables gave rise to the orthogonality condition:

$$
E\left[u(t) \backslash x_{1}(t), x_{2}(t), \ldots \ldots, x_{k}(t)\right]=0
$$

A violation of this condition leads to the endogeneity problem which ultimately results into a spurious regression (Seddighi et al, 2000). The instruments orthogonality condition also requires that the instruments used in the 2SLS be exogenous, a violation of which results also into a spurious regression and corrupts the validity of the instruments. This is particularly true when lagged dependent variables are included in the regression equation. 
For an efficient econometric exercise therefore, where it is suspected that some variables are endogenous, it is important to test the null hypothesis that the error terms are uncorrelated with some or all the regressors against the alternative that they are correlated, although not with the instruments. A regressor is endogenous if it is explained by the instruments in the model, whereas exogenous variables are those which are not explained by the instruments. If the difference in J-Statistic is insignificant then accept the null hypothesis, i.e. the variable(s) is/are exogenous (Orekoya and Olowookere, 2012). Our result has also showed that the orthogonality restiction is complied with. Since the probabilities of the Obs*R-squared and ChiSquare are insignificant, there is no presence of serial correlation nor Heteroskedasticity in the estimation (See Tables 3-5)

\section{RESULTS}

We proceed to deduce from our result that productivity and investment in human capital; particularly investment in education has an elastic impact on the growth of the economy. This means that a percentage increase in productivity or investment in human capital causes a more than proportionate increase in the growth of the economy. This is highly significant even at one percent significant level. These elastic impacts of human capital and productivity on economic growth is transmitted through changes in demographics, such as increased total school enrolment, life expectancy, labour force participation, reduced fertility and infant mortality rates. This means that improvements in demographic trend surely increase economic growth through its positive impacts on productivity. Human capital investment in health proved to be inelastic but very significant. We can accept that budgetary misappropriation; lack of budget discipline and implementation might also help us in understanding the reasons behind the inelastic nature. The Adjusted R-squared of 0.969513 show us that $96 \%$ of the variations in economic growth can be explained from productivity and investment in human capital. A high F-Statistic and the significances of its probability show that the model is relevant in explaining these effects.

\section{CONCLUSION AND RECOMMENDATIONS}

Based on these diagnostic tests, this study confirms that productivity and investment in human capital, particularly investment in education has an elastic impact on the growth of the economy. It proceeds to recommend that government should endeavour to ensure compliance with the United Nations and World Health Organization benchmark on expenditure/investment on education and health. This will enhance a productive demographic trend in the country via the exploitation of the country's demographic window of opportunity. Furthermore, it should be emphasized here that no nation could develop beyond its investment in education.

\section{References}

Axinn, W (1993) “The Effects of Children’s Schooling on Fertility Limitation”. Population Studies, 47:3, 481 - 493.

Bloom, D, Canning, D and Fink, G (2009) "Fertility, Female Labour Force Participation and Demographic Dividend". Journal of Economic Growth 14 (2) 79 - 10

Bloom, D and Caning, D (2001) “Cumulative Causality, Economic Growth and Demographic Transition” In: Birdsall, A Kelley and S.Sinding "Population Matters, Demographic Change, Economic Growth and Poverty in the Developing World.

Oxford: Oxford University Press.

Bloom, D and Williamson, J (1998) “Demographic Transition and Economic Miracles in Emerging Asia. World Bank Economic Review 12(3) 419-455.

Bongaarts, J and Casterline, J. (2012) “Fertility Transition: Is sub - Saharan Africa Different”? Population and Development Review, 38, 153-168. 
Campbell, O. A., \& Okuwa, O. B. (2016). Changing Demographics and Human Capital Development: Implications for Economic Growth in Nigeria. Archives of Business Research, 4(2), 161-176.

Caldwell, J (1982) Theory of fertility Decline. London: Academic Press Ltd.

Cochrane, S.H (2008) Fertility and Education: What Do We Really Know? Baltimore, MA, USA: The John Hopkins University Press.

Cohen, J (2011) “Top 10 key Population Trends on Earth”. Retrieved from Human World.

http://www.earthsky.org/2011 (accessed

Frini, Olfa and Muller, Christope (2012) “Demographic Transition, Education and Economic Growth in Tunisia”. Economic Systems. Vol.36 (3), 351-371. Doi: 10.1016/j.ecosys.2012.04.002

Galor, Q and Weil, D (2000) "Population, Technology and Growth: From Malthusian Stagnation to the Demographic Transition and Beyond”. American Economic Review, 90 (4): 806-828.

Goujon, A (2006) "Past and Future of Human capital in South - East Asia: From 1970 to 2030. Vienna Institute of Demography”, Academy of Science Working Paper 07/2006.

Gujarati, D. and Porter, D (2009) Basic Econometrics. 5th Edition. New York, Tata McGraw-Hill.

Higgins, M (1998) “Demography, National Savings and International Capital Flows”.

International Economic Review, 39 (2): 343 - 69.

International Labour Organization, (2012) "The Youth Employment Crisis: Time for Action Report V". International Labour Conference Proceedings, 101st Session, ILO, Geneva, June.

Jejeebhoy, Shireen (1996) Women's Education Autonomy and Reproductive Behaviour: Experience from Developing Countries. Oxford: Clarendon Press.

Kalemli- Ozcan, S (2002) “Does Mortality Decline Promote Economic Growth”|. Journal of Economic Growth, 7(4), 411-39.

Kelly, A and Schmidt, R (1995) “Aggregate Population and Economic Growth Correlations: The Role of the Components of Demographic Change". Demography. 32, 543 -55.

Lucas, Robert (1988) “The Mechanics of Economic Development”. Journal of Monetary Economics, 22, 3 - 42.

Makinwa- Adebusoye, Paulina (2014) Attaining Demographic Dividend in Nigeria. Award Winner Lecture Series. Ibadan. Jodad Publishers,

Ogawa, Naohiro and Retherland, Robert (1993) “The Resumption of Fertility Decline in Japan: 1973-92" Population and Development Review19 (4) Pp. 703 -741

Oni, Gbolahan (1985) The Effects of Women's Education on Postpartum Non-Susceptible in Ilorin, an Urban Community in Nigeria. Ann Arbor: Mich: University Microfilms International.

Orekoya Samuel and Olowookere Afolabi, (2012). Macroeconometrics Modelling and Simulations: Diagnostic Tests. Presented at the Macroeconomic model workshop organized by the Centre for Econometrics and Allied Research (CEAR). University of Ibadan. Between 26th - 30th Nov, 2012.

Oyinlola, M.A. (2012), Model Estimation. Macroeconomic Model Workshop, Centre for Econometrics and Allied Research (CEAR), University of Ibadan.

Prettner, K, Bloom, D and Strulik, H (2012) “Declining Fertility and Economic Well Being: Do Education and Health Ride to the Rescue"? IZA Discussion Paper No. 6527.

Pritchett, L (1997) “Divergence, Big Time”. Journal of Economic Perspectives, 11, (3), 3-17.

Ranis, G (2004) “Human Development and Economic Growth”. Center Discussion Paper,

No. 887. Economic Growth Center, Yale University. Retrieved from: http//www.econ.yale.edu

Romer, P (1986) “Increasing Returns and Long Term Growth” Journal of Political Economy 94(5), 1002- 1037.

Seddighi, H. R., Lawler, K. A., and Katos, A. V. (2000) Econometrics: A Practical Approach. New York. Routledge.

Schultz, T (1961) “Investment in Human Capital”, American Economic Review, 51, March. 
United Nations (2007) United Nations: State of the World Population. UN Population Division. UNFPA.

United Nations Development Programme (UNDP) Human Development Reports, 2006, 2011 and 2013, cited in Oladeji, S. I. Inaugural Lectures Series, 262. Educated and Qualified, but Jobless: A Challenge for Sustainable Development in Nigeria

Vogl, T (2014) “Differential Fertility, Human Capital and Development.” Princeton University. NBER and BREAD. Retrieved from: http// www.cireqmontreal.com

World Population Review (2014) World Population. World Bank World Development Indicators (2012) the World Bank.

\section{APPENDICES \\ TABLES}

Table 1: 2SLS2 RESULT

Dependent Variable: LNRGDP

Method: Two-Stage Least Squares

Date: 07/12/14 Time: 18:33

Sample (adjusted): 1990- 2010

Included observations: 21 after adjustments

Instrument specification: LNTSE LNLE LNLFP LNFR LNIMR

LNSTJ LNINF LNRGH

${ }^{2}$ Two - Stage Least Squares

Constant added to instrument list

\begin{tabular}{lllll}
\hline \hline Variable & \multicolumn{2}{l}{ Coefficient Std. Error } & t-Statistic & Prob. \\
\hline \hline C & -9.851068 & 1.621946 & -6.073612 & 0.0000 \\
LNGDPW & 1.643510 & 0.147243 & 11.16187 & 0.0000 \\
LNRGE & 0.268885 & 0.049267 & 5.457748 & 0.0000 \\
LNRGH & -0.181250 & 0.055186 & -3.284328 & 0.0044 \\
\hline \hline R-squared & 0.974086 & Mean dependent var & 12.88979 \\
Adjusted R-squared & 0.969513 & S.D. dependent var & 0.379830 \\
S.E. of regression & 0.066321 & Sum squared resi & 0.074773 \\
F-statistic & 215.8498 & Durbin-Watson stat & 1.721182 \\
Prob ${ }^{5}$ (F-statistic) & 0.000000 & Second-Stage SSR & 0.037216 \\
J-statistic & 7.142743 & Instrument rank & 9 \\
Prob(J-statistic) & 0.210239 & & & \\
\hline \hline
\end{tabular}

${ }^{3}$ variable, ${ }^{4}$ residual, ${ }^{5}$ statistic, ${ }^{6}$ probability

Table 2: Ramsey RESET Test

Equation: UNTITLED

Specification: LNRGDP C LNGDPW LNRGE LNRGH

Instrument specification: LNTSE LNLE LNLFP LNFR LNIMR

LNSTJ LNINF LNRGH

Omitted Variables: Squares of fitted values

\begin{tabular}{lll}
\hline \hline & Value $\mathrm{Df}^{7}$ & Probability \\
\cline { 2 - 3 } t-statistic & $0.544936 \quad 16$ & 0.5933 \\
F-statistic & $0.296956(1,16)$ & 0.5933 \\
Difference in J-stats & 0.8003720 & $\mathrm{NA}^{8}$ \\
\hline \hline
\end{tabular}

${ }^{7}$ degree of freedom, ${ }^{8}$ not available 
Table 3: Instrument Orthogonality C-test Test

Equation: UNTITLED

Specification: LNRGDP C LNGDPW LNRGE LNRGH

Instrument specification: LNTSE LNLE LNLFP LNFR LNIMR

LNSTJ LNINF LNRGH

Test instruments: LNFR LNIMR LNSTJ LNINF LNRGH

\begin{tabular}{llll}
\hline \hline & Value & Df & Probability \\
\cline { 2 - 4 } Difference in J-stats & 7.1427435 & 0.2102 \\
\hline \hline
\end{tabular}

J-statistic summary:

Restricted J-statistic $\frac{\text { Value }}{7.142743}$

Unrestricted J-

statistic $6.28 \mathrm{E}-28$

Table 4: Breusch-Godfrey Serial Correlation LM Test

\begin{tabular}{llll}
\hline \hline Obs*R-squared & 0.284262 & Prob. Chi-Square(2) & 0.8675 \\
\hline \hline
\end{tabular}

Table 5: Heteroskedasticity Test: White

\begin{tabular}{lrll}
\hline \hline F-statistic & 0.538596 & Prob. F(9,11) & 0.8190 \\
Obs*R-squared & 6.423442 & Prob. Chi-Square(9) & 0.6969 \\
Scaled explained SS 13.12785 & Prob. Chi-Square(9) & 0.1569
\end{tabular}

